\title{
La pandemia de la Covid-19 y la Diablada Pillareña
}

\section{The Covid-19 pandemic and the Diablada Pillareña}

1 Gabriela Lizeth Toapanta Inte

https://orcid.org/0000-0002-9299-0309.

Universidad Técnica de Ambato, Carrera de Turismo y Hotelería, Facultad de Ciencias

Humanas y de la Educación. Ambato, Ecuador.

gtoapanta8382@uta.edu.ec

2 Myriam Elizabeth Viteri Toro

iD https://orcid.org/0000-0001-7690-539X

Universidad Tecnológica Indoamérica, Carrera de Psicología, Facultad de Ciencias

Humanas y de la Salud. Ambato, Ecuador.

mviteri9@indoamerica.edu.ec

3 María Fernanda Viteri Toro

https://orcid.org/0000-0003-2600-7115.

Universidad Técnica de Ambato, Carrera de Turismo, Facultad de Ciencias Humanas y de

la Educación. Ambato, Ecuador.

mf.viteri@uta.edu.ec

$4 \quad$ Yadira Alexandra Proaño Gómez

https://orcid.org/0000-0003-1189-5316

Universidad Técnica de Ambato, Carrera de Turismo, Facultad de Ciencias Humanas y de

la Educación. Ambato, Ecuador.

ya.proano@uta.edu.ec

\begin{tabular}{r}
\hline Artículo de Investigación Científica y Tecnológica \\
Enviado: $24 / 12 / 2021$ \\
Revisado: $29 / 12 / 2021$ \\
Aceptado: $12 / 01 / 2022$ \\
Publicado:08/03/2023 \\
DOI: $\underline{\text { https://doi.org/10.33262/concienciadigital.v6i1.4.2049 }}$
\end{tabular}

Cítese:

Toapanta Inte, G. L., Viteri Toro, M. E., Viteri Toro, M. F., \& Proaño Gómez, Y. A. (2023). La pandemia de la Covid-19 y la Diablada Pillareña. ConcienciaDigital, 6(1.4), 1046-1063. https://doi.org/10.33262/concienciadigital.v6i1.4.2049

CONCIENCIA DIGITAL, es una Revista Multidisciplinar, Trimestral, que se publicará en soporte electrónico tiene como misión contribuir a la formación de profesionales competentes con visión humanística y crítica que sean capaces de exponer sus resultados investigativos y científicos en la misma medida que se promueva mediante su intervención cambios positivos en la sociedad. https://concienciadigital.org _

La revista es editada por la Editorial Ciencia Digital (Editorial de prestigio registrada en la Cámara Ecuatoriana de Libro con No de Afiliación 663) www.celibro.org.ec 


\section{Palabras} claves:

Diablada

Pillareña, pandemia, patrimonio cultural, alternativas seguras.

Keywords:

Diablada

Pillareña, pandemic, cultural heritage, safe alternatives.
Resumen

Introducción. La presente investigación se enfoca en el estudio de la festividad mayor del cantón Santiago de Píllaro, denominado “La Diablada Pillareña', misma que fue declarada Patrimonio cultural Inmaterial del Ecuador, por lo cual su importancia es considerable para sus habitantes. Sin embargo, tras la llegada de la pandemia por covid-19, que desato la interrupción abrupta de eventos sociales y culturales, dicha festividad fue cancelada provocando malestar e inconformidad en la comunidad Pillareña que espera su reactivación. Objetivo. Socializar los resultados de la relación de la pandemia de la Covid-19 y la festividad de la Diablada Pillareña. Metodología. El desarrollo de la investigación será mixto, debido al deseo por formar parte de la tradicional fiesta de la Diablada Pillareña y vivirla en todas sus diferentes formas, anteponiendo la salud y seguridad tanto de los turistas como de sus habitantes, fomentando así desarrollo turístico y el rescate del patrimonio cultural intangible del cantón Santiago de Píllaro. Resultados. La festividad de la Diablada Pillareña es esencial en el desarrollo económico, cultural y turístico del cantón Píllaro, siendo casi en su totalidad los emprendedores y artesanos que se apoyan en dicha fiesta para crear, innovar y comercializar sus productos o servicios, creando alternativas seguras para entretenimiento de los turistas durante la pandemia. Conclusión. La Diablada Pillareña forja un vínculo cultural identitario con la población del Cantón Píllaro, así mismo apoya el crecimiento económico y turístico, por lo cual es necesario conocer otras maneras de vivir la festividad de forma segura durante la pandemia.

\section{Abstract}

Introduction. This research focuses on the study of the major festival of the Santiago de Píllaro canton, called "La Diablada Pillareña", which was declared as Intangible Cultural Heritage of Ecuador, therefore, its importance is considerable for its inhabitants. However, after the arrival of the covid-19 pandemic, which unleashed the abrupt interruption of social and cultural events, this festival was canceled, causing upset and discontent in the Píllaro community that awaits its reactivation. Objective. Socialize the results of the relationship of the Covid-19 pandemic and the Diablada Pillareña festival. Methodology. The development of the research will be mixed, due to the desire to be 
part of the traditional festival of Diablada Pillareña and live it in all its different forms, putting the health and safety of both the tourist and its inhabitants first, thus promoting tourism development and the rescue of the intangible cultural heritage of the canton Santiago de Píllaro. Results. The Diablada Pillareña is essential in the economic, cultural and tourist development of the Píllaro canton, being almost entirely the entrepreneurs and artisans who trust this festival to create, innovate and commercialize their products or services, creating safe alternatives to tourist entertainment during the pandemic. Conclusion. The Diablada Pillareña forges a bond of cultural identity with the Píllaro's population, likewise, supports economic and tourist growth, so it is necessary to know other ways to live the festival safely during the pandemic.

\section{Introducción}

La Organización Mundial de la Salud (OMS, 2019), recibió informes de casos de neumonía y problemas respiratorios sin causa aparente en la ciudad de Wuhan, China. Para el mes de enero las autoridades concluyeron que se trataba de una nueva enfermedad infecciosa provocada por el coronavirus, a la que denominaron SARS-CoV-2 (Covid-19), el virus se propago rápidamente por todo el mundo frente a la incapacidad de contenerlo o erradicarlo al ser nuevo y desconocido para todos, las investigaciones sobre su procedencia los llevaron a un posible origen animal, derivado del murciélago (Bupa, 2020).

Las investigaciones para conocer el origen de la covid-19, llevo a un mercado de animales procesados y animales vivos en Wuhan, donde las altas demandas de proteínas han llevado a la venta de animales exóticos como culebras y murciélagos. De acuerdo con Koury y Hirschhaut (2020), las pésimas condiciones de insalubridad en el sector son la fuente de transmisión de enfermedades entre animales y de animales a personas, siendo este la cuna de nuevas enfermedades como la que se vive actualmente.

\section{Causas de la covid-19}

La propagación de la covid-19 se produce de persona a persona, al estar en contacto con un individuo infectado por medio de gotas respiratorias que son liberadas inadvertidamente al toser, hablar y estornudar, estas entran directamente por la nariz, boca y ojos de las personas. Sin embargo, el contagio es poco probable a una distancia de 2 metros, esta información fue útil para crear las medidas de prevención contra la covid-19. Según Giménez y Piera (2020), el periodo entre el contagio y la aparición de síntomas es 
de 7 a 14 días, por lo cual la cuarentena se establece en este lapso para confirmar o desestimar contagios.

\section{Efectos de la covid-19}

Las medidas gubernamentales anti-covid golpearon a la ciudadanía muy fuerte, pues los efectos producidos por las mismas afectaron su normal desarrollo de actividades, dejaron a varias personas en el desempleo y muchas otras perdieron sus negocios, la crisis económica creció a la par de los contagios y muertes, además, la población se enfrentó al peor de sus problemas, el miedo irracional a la enfermedad, las personas se convirtieron en sus principales enemigos y la histeria colectiva trajeron consigo el desabastecimiento de alimentos y productos de higiene, limpieza y desinfección que eran esenciales para protegerse.

\section{Sintomas}

La covid-19 afecta a las personas de manera diferente, ya sea de forma leve hasta grave, las personas pueden presentar varios síntomas como fiebre, cansancio, dolor de cabeza, dificultad para respirar, perdida del gusto, dolor de pecho, tos seca y diarrea. De acuerdo con la OMS (2021), identificar el nivel de síntomas que tiene una persona infectada permite tratar la enfermedad de forma eficaz y sin provocar la saturación de los centros de salud con pacientes que pueden ser tratados en casa. Cualquier persona puede infectarse, en especial los grupos de atención prioritaria debido a su condición de vulnerabilidad ante la pandemia, tal es el caso de los adultos mayores, personas con discapacidad y personas con afecciones medicas subyacentes.

\section{La pandemia y el turismo}

El turismo se ha convertido en una de las principales actividades involucradas en el crecimiento económico y generadoras de empleo, el turismo es un fenómeno social que abarca a varios grupos de interés, turistas, personas, gobierno y destinos. De acuerdo con Becerra y Orellana (2021), el turismo tiene la característica de dinamizar la economía y crear oportunidades en los lugares de destino turístico, por lo cual este sector está en crecimiento y en algunos países se ha convertido en su actividad principal.

La razón por la cual la pandemia a afectado tanto al turismo es porque la movilización constante de turistas que produce esta actividad es una de las principales fuentes de contagios, lo que resulto en 540 millones de dólares en pérdidas económicas provenientes del sector turístico, esto nos da una idea del impacto de la covid-19 en la economía y la importancia del turismo en el desarrollo sostenible del país. Sin embargo, antes de la aparición de la covid-19 en el entorno ecuatoriano, el turismo del país ya presentaba deficiencias que se acrecentaron con la llegada de la pandemia. 


\section{La pandemia y las celebraciones culturales}

La situación en la que dejo sumida la pandemia al mundo entero hizo replantearse a las autoridades nacionales sobre la importancia de salvaguardar el patrimonio cultural inmaterial del país. Según el Instituto Nacional de Patrimonio Cultural (s.f.), se han encargado de investigar y conocer el estado en el que se encuentra los saberes tradicionales y las prácticas culturales del país, por medio de conversaciones virtuales con los portadores, con quienes se ha tratado temas referentes al impacto que ha tenido la covid-19 en las practicas ancestrales de los pueblos y comunidades. Las comunidades reafirman la importancia de mantener vivas sus tradiciones y celebraciones culturales, concuerdan en el valor de transmitir su patrimonio a las futuras generaciones para fortalecer el legado cultural ancestral y pueda resistir aun en situaciones como la que se vive a causa de la crisis sanitaria que ha azotado al mundo entero.

De acuerdo con Cevallos (2020), la abrupta suspensión de las celebraciones culturales causó malestar en la población que esperaba con ansias su llegada, pero la rápida respuesta de las autoridades ayudo a minimizar dicho malestar, para ello adaptaron las festividades a formatos digitales, medida que permitió llegar a más personas tanto a nivel Nacional e internacional.

\section{Cantón Píllaro: Diablada Pillareña}

Santiago de Píllaro es un cantón perteneciente a la provincia de Tungurahua, Ecuador, a $14 \mathrm{~km}$ del cantón Ambato. Su nombre proviene del kichwa, pillalla que significa rayo y aroque altar, por lo tanto, se lo conoce como "el altar del Dios trueno". El turismo es una actividad importante del cantón, destacando el turismo religioso, cultural, agroturismo, observación de aves, de deportes y gastronómicos. Por otra parte, las expresiones culturales contribuyen al desarrollo social del cantón a través de la celebración de festividades como la Diablada Pillareña que se celebra del 1 al 6 de enero.

\section{Origen de la festividad}

Si bien su origen no tiene bases históricas, muchos historiadores se aventuran a crear sus propias versiones, como encontrar su origen con la llegada de los mitimaes de Bolivia y Perú y posteriormente la concesión de los hacendados para que los indígenas puedan celebrar con un desfile en año nuevo. De acuerdo con Tirado y Mora (2019), registros orales manifiestan que su origen está en la representación de La Legión, cuyo principal personaje era el diablo, del cual se inspiraron para dar nombre a la Diablada Pillareña. Sin embargo, el cronista Luis Lara, expresa que hay toda una historia detrás de su origen, cuenta que esta festividad nació de la disputa entre dos caseríos, Marcos Espinel y Tunguipamba, los hombres de Marcos Espinel acudían a cortejar a las mujeres de Tunguipamba, por lo que los celosos padres y hermanos de las muchachas se disfrazaron 
de diablos para ahuyentar a los enamorados.

\section{Organización}

De acuerdo con Endara (2021), la organización de la Diablada Pillareña se la realiza con meses de anticipación a través de acuerdos entre el Municipio de Píllaro, gestores culturales en conjunto con los cabecillas que representan a sus respectivas partidas de diablos. Sin embargo, el municipio es quien toma las decisiones finales en cuanto a la planificación de hfiesta, se encarga de financiar las partidas, establecer el cronograma de participación, los recorridos y descansos, esto permite que los cabecillas puedan organizar las partidas internamente, contratar la banda, preparar la coreografía de las parejas de línea, entre otras.

\section{Desarrollo de la festividad}

La Diablada Pillareña se desarrolla del 1 al 6 de enero, a las 2 de la tarde empieza el desfile que tiene lugar en las principales calles del cantón rodeadas por una multitud de espectadores con quienes interactúan los participantes del desfile, de acuerdo con el Ministerio de Turismo (2017), los participantes avanzan bailando al son de la banda de pueblo, las guarichas, diablos y capariche bailan alrededor de las parejas de línea, rodean la ciudad hasta retirase a su respectivo descanso, donde comen y bailan por unas horas hasta que llegue el momento de volver a desfilar antes de retirarse a sus respectivos hogares.

\section{Personajes}

La Diablada Pillareña es una celebración tradicional que identifica al cantón Santiago de Píllaro, esta manifestación cultural sobresale por sus llamativos personajes que inundan las calles del cantón del 1 al 6 de enero. En palabras de Carrasco (2017), la fiesta está conformada por el Diablo, las guarichas, el capariche, las parejas de línea, la banda y el cabecilla.

El diablo: son los principales actores de la Diablada Pillareña, sus pasos son enérgicos y van coordinados al son de la banda de pueblo, algo característico de estos personajes son sus gritos a mitad del desfile, gritan 'banda" cuando la música deja de sonar pidiendo que vuelvan a tocar, también está el tradicional y reconocido "Achachay", este singular grito es un símbolo de que los diablos sienten frio porque salieron del infierno.

Guarichas: la guaricha originalmente es un hombre vestido de mujer, aunque desde hace años la mujer también se disfraza de este personaje, representan a una madre soltera por lo que llevan un muñeco, estos personajes son los que llevan la alegría a la comparsa porque comparten su botella de trago con los espectadores e incluso los sacan a bailar. 
Capariche: este personaje es el que va al frente de la comparsa, acompañado con una escoba hecha de ramas con la cual además de bailar, también se encarga de barrer las calles y a la vez los pies de los espectadores, este es un recurso para animar a las personas.

Bailarines de línea: de acuerdo con Amores (2021), la pareja de línea la conforman un hombre y una mujer que se visten elegantemente, esto porque representan a la clase alta de esa época, estos personajes bailan en el centro de la comparsa al son de la música.

El cabecilla: es la persona a cargo de la organización y coordinación de la partida a la que representa, sus funciones son las de organizar a los participantes previo al desfile, además, se encarga de cubrir parte de los gastos de la partida.

La banda: se encargan de entonar la música tradicional que acompañara a las diferentes partidas que participen de la festividad, la banda es una parte esencial en el desarrollo de la festividad porque es quien pone el ritmo de baile ya sean sanjuanitos, saltashpas, tonadas y pasacalles.

\section{Indumentaria}

Los personajes que intervienen en la Diablada Pillareña, se distinguen por su singular y característica vestimenta, como se detalla a continuación:

Tabla 1

Indumentaria de los personajes

\begin{tabular}{ll}
\hline \multicolumn{1}{c}{ Personaje } & \multicolumn{1}{c}{ Descripción } \\
\hline & $\begin{array}{l}\text { Porta una vestimenta multicolor: los colores tradicionales eran rojo y dorado, } \\
\text { actualmente se utilizan más colores que hagan más llamativo el traje. }\end{array}$ \\
& $\begin{array}{l}\text { Coronilla: fabricada en cartón y papel celofán, material utilizado para brillar en la } \\
\text { noche, actualmente añaden cuernos y otros accesorios para resaltar más la figura del } \\
\text { personaje. }\end{array}$ \\
& $\begin{array}{l}\text { Careta: elaborada en cartón, papel y decorada con cuernos, dientes y similares para } \\
\text { darle la apariencia de aterrador, la cantidad de cuernos en una careta representa la }\end{array}$ \\
& jerarquía del diablo. \\
& $\begin{array}{l}\text { Pantalón corto: confeccionado en tela espejo hasta las rodillas, el diseño tradicional } \\
\text { es en color rojo con flecos dorados. Sin embargo, su diseño ha } \\
\text { cambiado y hoy existen varios modelos. }\end{array}$ \\
\hline
\end{tabular}




\section{Tabla 1}

\section{Indumentaria de los personajes (continuación)}

\begin{tabular}{|c|c|}
\hline Personaje & Descripción \\
\hline \multirow{7}{*}{ Diablo } & $\begin{array}{l}\text { Blusa: confeccionado en tela espejo, mismas características que el pantalón, } \\
\text { también ha sufrido variaciones con el paso de los años. }\end{array}$ \\
\hline & $\begin{array}{l}\text { Capa: elaborada en tela espejo, también tiene flecos, actualmente varias } \\
\text { personas han prescindido de utilizar este accesorio en sus trajes. }\end{array}$ \\
\hline & Pañuelo: de seda, utilizado para cubrir la cabeza. \\
\hline & Medias: color carne en talla única. \\
\hline & Guantes: de lana en color negro. \\
\hline & Zapatillas: de lona color negro. \\
\hline & $\begin{array}{l}\text { Acial o fuete: hecho de pata de venado, usualmente lo llevan en la mano } \\
\text { derecha. }\end{array}$ \\
\hline \multirow{8}{*}{ Pareja de línea } & $\begin{array}{l}\text { Sombrero: los hombres usan sombrero elaborado en cartón y decorado en papel } \\
\text { celofán } \\
\text { Coronilla: las mujeres utilizan una coronilla de cartón. }\end{array}$ \\
\hline & Mascara: de malla \\
\hline & $\begin{array}{l}\text { Pañuelo de seda: el hombre utiliza } 2 \text { pañuelos uno para cubrir la espalda y otro } \\
\text { para la cabeza, mientras que la mujer un pañuelo que cubre la coronilla. }\end{array}$ \\
\hline & $\begin{array}{l}\text { Camisa y pantalón: el hombre lleva camisa de color blanco y pantalón de tela } \\
\text { color negro decorado con papel celofán. }\end{array}$ \\
\hline & Vestido: la mujer utiliza un vestido plisado de colores llamativos. \\
\hline & Zapatos: el hombre usa zapatos negros y la mujer usa zapatos negros de taco bajo. \\
\hline & Guantes y pañuelo: blancos \\
\hline & $\begin{array}{l}\text { Sombrero: utiliza un sombrero negro decorado con cintas de colores que } \\
\text { cuelgan del sombrero, también es adornado con monedas y espejos. }\end{array}$ \\
\hline \multirow{8}{*}{ Guaricha } & $\begin{array}{l}\text { Pañuelo de seda: utilizan uno en la cabeza y otro lo colocan en la espalda como } \\
\text { una capa. }\end{array}$ \\
\hline & Mascara: de malla \\
\hline & $\begin{array}{l}\text { Camisón largo: decorado con cintas de colores, lazos, billetes y espejos que lo } \\
\text { hagan ver vistoso. }\end{array}$ \\
\hline & Medias: color piel \\
\hline & Zapatillas: de lona color negro. \\
\hline & Muñeca: representa al hijo de la guaricha que es una madre soltera. \\
\hline & $\begin{array}{l}\text { Shigra: son bolsas artesanales en las que llevan su botella de trago para brindar } \\
\text { a los espectadores. }\end{array}$ \\
\hline & Acial o fuete: hecho de pata de cabra. \\
\hline
\end{tabular}


Tabla 1

Indumentaria de los personajes (continuación)

\begin{tabular}{|c|c|}
\hline Personaje & Descripción \\
\hline \multirow{9}{*}{ Capariche } & Sombrero: de color blanco \\
\hline & Pañuelo de seda: lo utilizan para cubrir la cabeza. \\
\hline & Mascara: de malla. \\
\hline & Poncho: hecho de lana de color rojo, lo utilizan doblado. \\
\hline & Camisa y pantalón: de tela color blanco. \\
\hline & Faja: para amarrar la cintura alrededor del poncho. \\
\hline & Zapatillas: de color blanco o negro. \\
\hline & Guantes: de color blanco. \\
\hline & $\begin{array}{l}\text { Escoba: elaborada con ramas, ortigas y espinos, la utilizan para barrer los pies } \\
\text { de las personas. }\end{array}$ \\
\hline
\end{tabular}

Fuente: Carrasco (2017)

\section{Patrimonialización}

La Diablada Pillareña es una manifestación de la cultura indígena-mestiza y una de las más importantes que se realiza en el país desde hace algunos años. El desarrollo de esta festividad se realizaba de manera desordenada por lo que se crea el departamento de cultura cuyo fin era conseguir la patrimonialización de la Diablada, por lo que en el 2005 nace la iniciativa para revitalizar esta práctica ancestral y rescatar el valor cultural que aporta al pueblo de Píllaro, consiguiendo años más tarde la declaración de patrimonio.

El Ministerio de Cultura, mediante Acuerdo Ministerial No. 147, del 29 de diciembre del 2008, declara como bien perteneciente al Patrimonio Cultural Inmaterial del Estado, a la "Diablada Pillareña", dentro de un marco de conceptos y principios internacionales emanados desde la Unesco y, un marco nacional desde la perspectiva de un Estado, que busca la aprobación internacional a través de acatar sus disposiciones y coincidir con la tendencia mundial de su manejo y conceptos sobre la salvaguardia del patrimonio cultural inmaterial, bajo el discurso de la reivindicación de la gestión cultural en el país.

Luego de esta declaratoria, la festividad tuvo muchos cambios favorables, pues dio un empuje al turismo y pudo ser conocido no solo a nivel nacional sino también internacional, este gran logro fue celebrado el 4 de enero del 2009 en medio de un evento que contaba con la participación de las autoridades del cantón, la banda y los diablos que bailaban alegremente. 


\section{Dinamización de la economía}

El patrimonio cultural es concebido como un producto turístico generador de ingresos económicos, es así como la Diablada Pillareña al ser la fiesta mayor de cultura y tradición del cantón Píllaro es dinamizadora de la economía a nivel local, pues reúne a un gran número de personas en el centro de la ciudad. De acuerdo con Landy (2019), en época de fiestas los artesanos y manos pillareñas trabajan arduamente para cumplir con la demanda de productos.

\section{Turismo}

La Diablada Pillareña fortalece la cultura del cantón Santiago de Píllaro y su patrimonialización la ayudo a sobresalir internacionalmente, tanto así que atrae todos los años a cientos de turistas nacionales y extranjeros a vivir de cerca esta expresión cultural. El cantón Píllaro posee distintos pisos climáticos que han favorecido a su biodiversidad, cuenta con recursos naturales que son interesantes ante cualquier persona, existen también, varios centros recreativos que permiten a los turistas estar en contacto con la naturaleza mientras disfrutan de actividades de esparcimiento familiar. Los talleres de caretas de diablos también son sitios visitados por los turistas porque sus llamativos diseños no permiten que las personas se vayan del cantón sin llevarse una careta, artesanía o llavero.

\section{Gastronomía}

La gran afluencia de turistas que llegan al cantón Píllaro por motivo de la celebración de la Diablada Pillareña, ha dado paso a que la gastronomía local sobresalga. Es así como, varios platos tradicionales y típicos han resurgido del olvido, otros se han popularizado a nivel nacional e incluso traspasado las fronteras, para Ramírez (2019), en el caso del pato al lodo que fue rescatado por Don Ángel, tuvo que pasar mucho tiempo estudiando su elaboración para poder perfeccionarlo y ofrecerlo al público, convirtiéndose en el plato representativo de la gastronomía pillareña.

Asimismo, un plato bastante popular en los principales centros recreativos comunitarios es la trucha en cualquiera de sus presentaciones, todos los restaurantes cuentan con su propio criadero de truchas para garantizar la calidad del plato, los mercados son otro lugar favorito por los turistas para disfrutar de platos como el caldo de 31, morcilla, caldo de pata, cuycon papas, fritada y de bebidas tradicionales destacando el champús. A la oferta gastronómica del cantón se suma la nueva iniciativa identitaria, con el diablito y la Guaricha representados en pan, para rescatar el valor cultural de la festividad y para mantener vivas las tradiciones durante la pandemia. 


\section{Elaboración de caretas de diablo}

Las máscaras de diablo son la esencia de la Diablada Pillareña por sus llamativos y demoniacos diseños, su elaboración se remonta a la época colonial, pues la representación del cielo y el infierno llegaría al Ecuador con la inserción del catolicismo traído por los españoles. De acuerdo con Amores (2021), las máscaras de los diablos son fabricadas artesanalmente por manos pillareñas, desde sus inicios hasta la actualidad las técnicas de elaboración han sido mejoradas y por ende la calidad y diseños.

La técnica empleada para la elaboración de las máscaras es la de papel engomado que consiste a su vez en dos técnicas, la de papel cartapesta o capa sobre capa, se aplica sobre el molde y una vez seco se retira, y la de papel mache que es una pasta de papel con la cual se trabaja los relieves de la careta, la expresión de las caretas muestra una nariz aguileña, su boca abierta enseñando los colmillos y el ceño fruncido, los diseños han cambiado de los tradicionales por lo que ahora se utilizan cuernos y dientes reales ya sea de cabras, corderos o toros, observar su proceso de elaboración es un recurso turístico útil para quienes desean ser parte de la festividad durante la pandemia.

Luego de todo lo expuesto anteriormente en base a ambas variables de estudio, para entender el caso de estudio se aplica la teoría de los sistemas sociales de Niklas Luhmann, esta teoría permite percibir a la cultura como un fenómeno social universal porque se extiende por todo el mundo, al igual que la covid-19. En este sentido, los efectos que produce la covid-19 en las acciones humanas también influirán en las culturas de todo el mundo, con los resultados vistos hasta hoy es evidente los cambios producidos en la sociedad por la nueva enfermedad, en el caso específico de la Diablada Pillareña, el impacto ha sido mayor en la ciudadanía local, pues esta festividad está vinculada a la identidad cultural del pueblo pillareño. De acuerdo con Cadenas (2014), la base de la sociedad es la comunicación y por tanto la cultura se transmite mediante la comunicación de la sociedad, así pues, el baile en la Diablada Pillareña es la principal forma de comunicación entre personas.

\section{Metodología}

El diseño de la investigación a realizarse es mixto, consiste en un conjunto de métodos de recolección, mezcla y análisis de un estudio investigativo cualitativo y cuantitativo. Este proceso sistemático es de carácter empírico y crítico de investigación, así mismo se encarga de extraer las fortalezas y de minimizar las debilidades de los métodos cualitativo y cuantitativo. Su alcance es exploratorio fenomenológico. Con un diseño no experimental de corte horizontal.

Para su desarrollo, se estableció 3 etapas, divididas en fichas del INPC, encuestas y la respectiva validación y análisis de esta, en cuanto a un enfoque retrospectivo del 
desarrollo de la festividad de la Diablada Pillareña.

\section{Etapa 1.- Fichas del INPC}

En la primera etapa, se procedió a realizar el levantamiento de información respectivo en fichas aprobadas por el INPC, instrumento cualitativo que sirve para recolectar información de manera práctica y ordenada, en este sentido se buscada conocer información acerca de la festividad de la Diablada Pillareña y sus componentes artesanales y gastronómicos principales que intervienen directamente en la realización de dicha manifestación cultural.

\section{Etapa 2.- Encuesta}

La encuesta elaborada consta de 4 secciones, la primera sección consta de 2 ítems de ámbito personal con preguntas cerradas; seguido del ámbito importancia de la Diablada Pillareña, comprendido en 5 ítems; posteriormente está el ámbito Diablada Pillareña antes de la pandemia que contiene 3 ítems y por último el ámbito Diablada Pillareña después de la

pandemia conformada por 4 ítems, las preguntas desarrolladas en estos 3 ámbitos tienen opciones de respuesta basadas en la escala de Lickert para conocer la situación actual y previa de la festividad y su desarrollo durante la pandemia. De esta manera se desarrolló un instrumento de recolección de 14 preguntas.

\section{Etapa 3.- Validación de instrumentos}

Luego del desarrollo de la encuesta, se procedió a realizar la respectiva validación cualitativa, al tratarse de un proyecto investigativo y debido a que la encuesta fue planteada bajo criterios académicos, se requirió la validación de docentes del área turística.

Una vez obtenida la respuesta de los expertos, se procedió a realizar la pertinente corrección del instrumento de acuerdo con las sugerencias del docente, manteniendo el objetivo y esencia de la encuesta realizada. Además, para obtener la fiabilidad del instrumento se aplicó el programa estadístico Alfa de Cronbach el cual permite medir la confiabilidad y determina el resultado del coeficiente de una totalidad de las aplicaciones para determinar que no existan errores en la prueba. Sus datos de interpretan de la siguiente manera: 
Tabla 2

Interpretación de Cronbach

\begin{tabular}{ll}
\multicolumn{1}{c}{ Variación numérica } & \multicolumn{1}{c}{ Interpretación } \\
\hline Entre $1,0-0,9$ & Instrumento de medición excelente \\
Entre $0,9-0,8$ & Instrumento bueno \\
Entre $0,8-0,7$ & Instrumento aceptable \\
Entre $0,7-0,6$ & Instrumento débil \\
Entre $0,6-0,5$ & Instrumento pobre \\
$<0,5$ & Instrumento no aceptable \\
\hline
\end{tabular}

Fuente: Coeficiente de Cronbach

Para determinar la fiabilidad del instrumento utilizado a través del programa estadístico Alfa de Cronbach se utilizó preguntas determinadas en escala, obteniendo un resultado de 0,7 que de acuerdo con la interpretación se considera un instrumento aceptable.

\section{Tabla 3}

Análisis de fiabilidad

\begin{tabular}{lcc}
\hline $\begin{array}{c}\text { Alfa de } \\
\text { Cronbach }\end{array}$ & $\begin{array}{c}\text { Alfa de Cronbach basada en } \\
\text { elementos estandarizados }\end{array}$ & $\begin{array}{c}\mathrm{N} \mathrm{de} \\
\text { elementos }\end{array}$ \\
\hline .741 & .741 & 6 \\
\hline
\end{tabular}

Fuente: Programa estadístico SPSS

\section{Resultados}

\section{Etapa 1.- Discusión: Fichas del INPC}

Para el levantamiento de información se hizo uso de tres fichas del INPC.

La ficha A3, Usos rituales, sociales y actos festivos, está relacionada con las practicas, manifestaciones y representación culturales espacio temporales. Por sus características permitió recopilar datos sobre la fiesta de la Diablada Pillareña, de forma ordenada, completa y de fácil comprensión.

La ficha A4, Conocimientos y usos relacionados con la naturaleza y el universo, trata sobre las técnicas y prácticas que las comunidades mantienen en relación con la naturaleza y sus creencias sobre temas gastronómicos. Por lo cual es útil para levantar información sobre el licor utilizado en la festividad.

La ficha A5, Técnicas artesanales tradicionales, hace énfasis en la aplicación de técnicas manuales. Lo que posibilita emplearla para reunir datos sobre la elaboración de máscaras de diablo e indumentaria de los personajes de la festividad. 


\section{Tabla 4}

Análisis y discusión de la encuesta

\begin{tabular}{ll}
\hline \multicolumn{1}{c}{ Pregunta } & \multicolumn{1}{c}{ Discusión } \\
\hline & ÁREA PERSONAL \\
\hline $\begin{array}{l}\text { 1.Cuál de las siguientes opciones describe } \\
\text { mejor la actividad o el área de servicio a } \\
\text { la que pertenece }\end{array}$ & $\begin{array}{l}\text { De las } 5 \text { opciones de respuesta, el área de servicio al que } \\
\text { pertenecen los dueños de negocios encuestados corresponde } \\
\text { a 16\% Talleres de máscaras de diablo; 18\% sastrerías: venta } \\
\text { y alquiler de trajes; 47\% locales en alimentos y bebidas, } \\
\text { siendoel mayor número de encuestados; 1\% Agencia de } \\
\text { viaje/operadora turística y 18\% en el área de transporte. }\end{array}$ \\
\hline $\begin{array}{ll}\text { 2. ¿Cuántos años de trayectoria tiene su } \\
\text { negocio? }\end{array}$ & $\begin{array}{l}\text { De la totalidad de encuestados, el 39\% de ellos tiene una } \\
\text { trayectoria de 6 a 15 años, seguido del 32\% que corresponde } \\
\text { a negocios menores a 5 años, el 20\% respondió de 16 a 29 } \\
\text { años ycon menor trayectoria de 26 a 39 años con el 7\% y con } \\
\text { más de 40 años apenas el 2\%. }\end{array}$ \\
& \\
\hline
\end{tabular}

IMPORTANCIA DE LA DIABLADA PILLAREÑA

3.Teniendo en cuenta el tiempo de trayectoria de su negocio. ¿Qué tan importante es la Diablada Pillareña en la demanda de su producto?
Con opciones de respuesta en escala de Lickert, los encuestados consideran en un 64\% que la Diablada Pillareña es muy importante en la demanda de sus productos, el $20 \%$ de ellos considera que es medianamente importante, mientras que para el $14 \%$ es importante, y por último el $2 \%$ de ellos consideran que es nada importante.

4. Dentro de su consideración, que tan importante piensa que es la Diablada Pillareña como festividad en la construcción de la identidad cultural para la población del cantón Píllaro.

En cuanto al aporte de la Diablada Pillareña a la identidad cultural, el $81 \%$ lo considera muy importante, mientras que el $10 \%$ piensa que es importante y para el $9 \%$ es medianamente importante, desestimando las opciones nada importante y poco importante.

5. Dentro de su consideración, que tan importante piensa que es la Diablada Pillareña como festividad en el desarrollo económico y turístico del cantón Píllaro.

En cuanto al desarrollo económico y turístico, los encuestados consideran; $66 \%$ muy importante, para el $12 \%$ es medianamente importante, el $19 \%$ de ellos lo consideran importante y tan solo el $3 \%$ piensa que es poco importante.

6. Está de acuerdo con la reactivación de la Diablada Pillareña para el año 2022
Luego de analizar la importancia de la Diablada Pillareña, el $68 \%$ de los encuestados estaban totalmente de acuerdo con su reactivación, el $15 \%$ respondieron medianamente de acuerdo y el 14\% estaban de acuerdo, por otra parte, el 3\% se pronunció en desacuerdo argumentando no obtener beneficios de la festividad.
7. Está satisfecho con respecto a los 3 días de Diablada Pillareña.
Las respuestas receptadas son variadas en cuanto al periodo de festividad, resultando en un $20 \%$ de encuestados totalmente satisfechos, el $38 \%$ de ellos esta medianamente satisfecho, el $33 \%$ esta regularmente satisfecho, mientras que en contra de este cambio el $3 \%$ esta medianamente satisfecho y el $6 \%$ está totalmente insatisfecho. 


\section{Tabla 4}

Análisis y discusión de la encuesta (continuación)

\begin{tabular}{cc}
\hline Pregunta & Discusión \\
\hline
\end{tabular}

\section{LA DIABLADA PILLAREÑA ANTES DE LA PANDEMIA}

8. Nivel de demanda de productos o servicios en los días no festivos de la Diablada Pillareña

9. Nivel de demanda de productos o servicios durante la Diablada Pillareña

En los días fuera de la Diablada Pillareña antes de la pandemia, el $75 \%$ de los negocios presentaban una demanda regular de sus productos, el 14\% medianamente alta y el $3 \%$ tenía demanda alta, mientras que para el $2 \%$ la demanda era muy baja y para el $6 \%$ baja.

En los 6 días de Diablada Pillareña, los negocios encuestados tenían un incremento significativo en su demanda, el 65\% presentaba una demanda alta, el 19\% medianamente alto, para el $11 \%$ sus negocios no mostraron cambios en el nivel de ventas manteniendo una demanda regular, mismo caso para el $2 \%$ con demanda muy baja y el $3 \%$ bajo.

10.Qué porcentaje de ganancias presentaba su negocio en años anteriores al 2020
Antes del 2020, el 14\% presentaba ganancias de más de 50\%, el $13 \%$ de encuestados dijo tener ganancias de entre $41-50 \%$; las opciones de respuesta de $21-30 \%$ y $31-40 \%$ presento el $32 \%$ para cada una y de $10-20 \%$ de ganancias obtuvo el $9 \%$ de encuestados.

\section{LA DIABLADA PILLAREÑA DURANTE LA PANDEMIA}

11. Nivel de demanda de productos o servicios en los días no festivos de la Diablada Pillareña en los años 2020 -2021

12. Nivel de demanda de productos o servicios durante la Diablada Pillareña en el año 2021
Durante la pandemia los negocios vinculados a la festividad se vieron afectados, resultando en la disminución de la demanda, para el $77 \%$ de encuestados la demanda fue muy baja, el $13 \%$ presenta demanda baja, para el $8 \%$ es regular y la demanda medianamente alta tan solo el $2 \%$ de encuestados.

El desarrollo virtual de la Diablada Pillareña no favoreció al incremento de la demanda, como en años anteriores, siendo así que el $61 \%$ mantiene demanda muy baja, el $27 \%$ bajo, el $7 \%$ regular, la demanda medianamente alta presenta el $4 \%$ de encuestados y alta solo para el $1 \%$.

La pandemia resulto en pérdidas de más del $50 \%$ en los negocios para el 67\% de encuestados, el 19\% de ellos tuvo pérdidas del $41-50 \%$, el $6 \%$ de los encuestados dijo tener pérdidas del $31-40 \%$, el $3 \%$ entre $21-30 \%$ y el $5 \%$ de 10 $20 \%$ de pérdidas.

14. Cuál de las alternativas presentadas a continuación considera la opción más viable para el desarrollo de la festividad durante la pandemia
De las 4 opciones de respuesta presentadas, el $76 \%$ de los encuestados manifestaron inclinarse por el desarrollo de la festividad por el centro del cantón como ha sido siempre, mientras que el $13 \%$ opto por alternativas a fin de reactivar la festividad prefiriendo el desarrollo en comunidades y el $11 \%$ prefiere que no se realice hasta que termine la pandemia.

Elaborado: Toapanta (2021) 


\section{Conclusiones}

- La investigación permite conocer sobre la enfermedad de la covid-19, sus orígenes, causas y efectos producidos en la actividad turística, manifiesta la necesidad de saber lo peligroso de la pandemia, pues su repentina aparición produjo serios problemas en el desarrollo cotidiano de la sociedad, resultando en la suspensión de actos sociales y culturales que por sus características reúne a cientos de turistas en un mismo lugar.

- La Diablada Pillareña es una festividad fuertemente arraigada a la cultura pillareña, por lo mismo, su desarrollo es de suma importancia para el cantón y sus pobladores pues es generadora de crecimiento económico y turístico. Antes de la llegada del virus al país se vivían 6 días de fiestas por el centro del cantón, lo que permitía prosperar a los negocios centralizados y en zonas turísticas, en la actualidad la fiesta lleva dos años de suspensión en donde los negocios que dependen de la Diablada Pillareña buscan alternativas seguras para continuar siendo rentables.

- Las pérdidas por la pandemia han sido significativas, pero son aún mayores en comparación a la demanda del 1 al 6 de enero, por lo que el pueblo pillareño busca alternativas que les permita comercializar sus productos como en épocas anteriores, muchos buscan crear nuevas marcas que, a más de proporcionar ingresos económicos, también sirve como estrategia para evitar la pérdida del valor cultural de la Diablada Pillareña.

\section{Referencias bibliográficas}

Amores, R. (06 de 05 de 2021). Entorno turístico. https://www.entornoturistico.com/ladiablada-de-pillaro-una-tradicion-de- resiliencia/

Becerra, F., Vega, J., \& Orellana, M. (10 de 04 de 2021). Digital publisher. file:///C:/Users/PC/Downloads/566-Art\%C3\%ADculo_manuscrito_ensayo4966-1 - 10-20210506.pdf

Bupa. (03 de 2020). https://www.bupasalud.com.ec/salud/coronavirus

Cadenas, H. (2014). Open editions journals. https://journals.openedition.org/polis/10487

Carrasco, C. (2017). Go raymi. https://www.goraymi.com/esec/tungurahua/pillaro/fiestas-tradicionales/diablada-pillarena-ajx53e6g3

Cevallos, D. (23 de 11 de 2020). El comercio. https://www.elcomercio.com/tendencias/entretenimiento/pandemiamodificacion- forma-fiestas-diciembre.html 
Endara, F. (12 de 01 de 2021). La Disputa. https://ladisputa.org/2021/01/12/ladiablada-de-pillaro-pandemia-e-insurgencia/

Giménez Serrano, S., \& Piera Fernández, M. (31 de 07 de 2020). Fisterra. https://www.fisterra.com/ayuda-en-consulta/informacion-parapacientes/enfermedad-por-coronavirus-2019-covid-19/

Instituto Nacional de Patrimonio Cultural. (s.f.). patrimoniocultural.gob. https://www.patrimoniocultural.gob.ec/patrimonio-cultural-inmaterial-frente-alcovid-19/

Koury, J., \& Hirschhaut, M. (23 de 03 de 2020). Acta Odontológica de Venezuela. https://www.actaodontologica.com/ediciones/2020/especial/art-2/

Landy, C. (07 de 11 de 2019). https://dspace.ucuenca.edu.ec/bitstream/123456789/33617/1/Trabajo\%20de\%20t itul aci\%C3\%B3n.pdf

Ministerio de Turismo. (27 de 12 de 2017). turismo.gob. https://www.turismo.gob.ec/ladiablada-pillarena-una-explosion-de-cultura-y-

alegria/\#: :text=g\%C3\%BCarichas\%20y\%20capariches.,Cuenta\%20la\%20leyen da\%20que\%20quienes\%20se\%20visten\%20de\%20diablos\%20en,toman\%20las $\% 20$ calles\%20de\%20P\%C3\%ADllaro.

Organización Mundial de la Salud [OMS]. (22 de 02 de 2021). Organización Mundial de la Salud. https://espanol.cdc.gov/coronavirus/2019-ncov/symptomstesting/symptoms.html

Ramírez, D. (12 de 02 de 2019). Gastronomía. https://ecuador.gastronomia.com/noticia/8682/tradicion-del-pillaro-pato-al-lodo

Tirado, D., \& Mora, A. (04 de 12 de 2019). redaly.org. https://www.redalyc.org/journal/5717/571763613009/html/

\section{Liencia}


El artículo que se publica es de exclusiva responsabilidad de los autores y no necesariamente reflejan el pensamiento de la Revista Conciencia Digital.

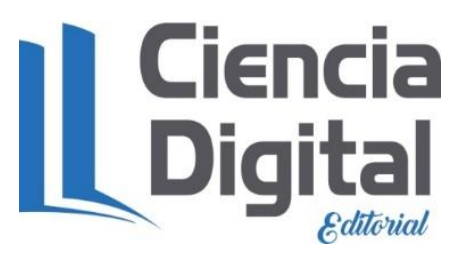

El artículo queda en propiedad de la revista y, por tanto, su publicación parcial y/o total en otro medio tiene que ser autorizado por el director de la Revista Conciencia Digital.
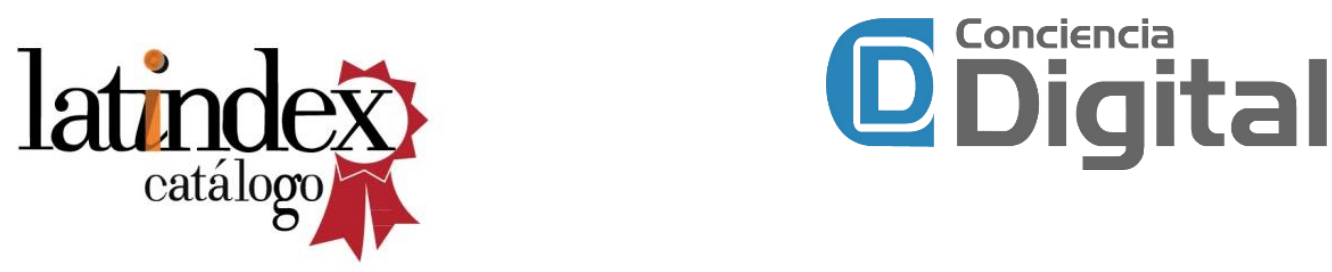

Indexaciones

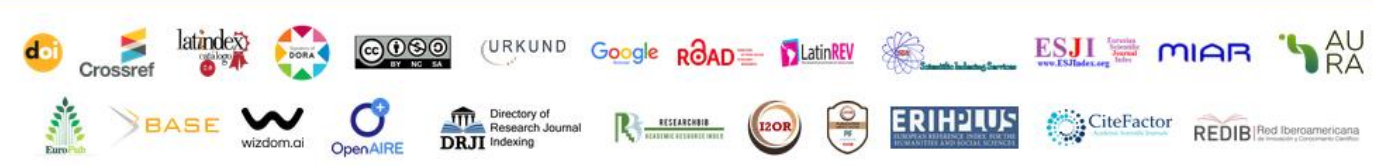

